\title{
Two pectin lyase genes, pnl-1 and pnl-2, from Colletotrichum gloeosporioides f. sp. malvae differ in a cellulose-binding domain and in their expression during infection of Malva pusilla
}

\author{
Yangdou Wei†, Jenny Shih, Jieran Li and Paul H. Goodwin†
}

Author for correspondence: Paul H. Goodwin. Tel: +1 5198244120 ext. 2754. Fax: +1 5198370442. e-mail:pgoodwin@uoguelph.ca

Department of

Environmental Biology,

University of Guelph,

Guelph, Ontario, Canada,

N1G 2W1
Two pectin lyase genes, designated $p n l-1$ and $p n l-2$, were cloned from Colletotrichum gloeosporioides $f$. sp. malvae, a pathogen of round-leaved mallow (Malva pusilla). pnl-1 was isolated using cDNA from infected plant material; pnl-2 was isolated using cDNA from 3-day-old mycelia grown in mallow-cell-wall extract (MCWE) broth. pnl-1 is the first pectinase gene described thus far to encode a cellulose-binding domain (CBD), which is common in cellulases and xylanases, whereas pnl-2 encodes a pectin lyase that lacks a CBD. In pure culture, pnl-1 expression could be detected when purified pectin or glucose was the sole carbon source, but not when MCWE was the sole carbon source. The lack of pnl-1 expression appeared to be due to gene repression by some unknown factor(s) in the cell-wall extract. In contrast, expression of pnl-2 was detected in cultures when MCWE, but not when purified pectin or glucose, was the sole carbon source. In infected tissue, detection of pnl-1 expression by Northern-blot hybridization and by RT-PCR began with the onset of the necrotrophic phase of infection. Expression of pnl-2 was not detectable by Northern-blot hybridization, but was observed by RT-PCR in both the biotrophic and necrotrophic phases of infection. The differences between pnl-1 and pnl-2 (i.e. pnl-1 encoding a CBD and differences in the expression patterns of both genes) may be related to the requirements of C. gloeosporioides f. sp. malvae to be able to grow in host tissue under the different conditions present during the biotrophic and necrotrophic phases of infection.

Keywords: anthracnose, biotrophy, hemibiotrophy, mallow, necrotrophy

\section{INTRODUCTION}

Colletotrichum gloeosporioides f. sp. malvae (Cgm) is a biological control agent developed for the control of round-leaved (Malva pusilla Sm.) and small-flowered

†These authors contributed equally to this work.

Abbreviations: $C B D$, cellulose-binding domain; CWDE, cell-wall-degrading enzyme; Cgm, Colletotrichum gloeosporioides f. sp. malvae; LPH, large primary hyphae; MCWE, mallow-cell-wall extract; PDA, potato dextrose agar; PEL, pectate lyase; PNL, pectin lyase; RACE, rapid amplification of CDNA ends; TSH, thin secondary hyphae.

The GenBank accession numbers for the sequences reported in this paper are AF158256 and AF156984.
(Malva parviflora L.) mallow (Makowski \& Mortensen, 1992). The fungus causes anthracnose in its host by an infection process known as intracellular hemibiotrophy, where an infection vesicle forms after penetration of a host epidermal cell and then spreads into adjacent cells by large primary hyphae (LPH). These fungal structures invaginate rather than penetrate the host cell membrane and, during this period, a biotrophic interaction persists in which the LPH are highly constricted as they penetrate the host cell. After a few days, thin secondary hyphae (TSH) grow from the LPH, and a necrotrophic interaction develops with no constrictions of the TSH as they grow through host cell walls (Morin et al., 1996; Wei et al., 1997). 
The interaction between Cgm and mallow indicates that cell-wall-degrading enzymes (CWDEs) produced by the fungus may be involved in disease development. Among fungal CWDEs, pectinases have been the most widely studied because pectic compounds are important to the structure of the plant cell wall and middle lamella, and pectinases alone can directly kill plant cells (Keon et al., 1987). A pectate lyase (PEL) gene of C. gloeosporioides has been shown to be important for the virulence of the fungus in avocado fruit (Yakoby et al., 2001), indicating that at least some pectinases are involved in the virulence of Colletotrichum. For Cgm, two PEL genes (pel-1 and pel-2) have been described thus far (Shih et al., 2000). Only pel-2 expression could be detected during infection or in pure culture with glucose as the sole carbon source, but both pel-1 and pel-2 transcripts could be detected in pure cultures with either mallow-cell-wall extract (MCWE) or purified apple pectin as sole carbon source. Pectic lyase enzyme activity, which includes both PEL and pectin lyase (PNL) activities, was detected in infected mallow leaves at the onset of the necrotrophic phase of infection, which is also the period when pel-2 transcripts were detected (Shih et al., 2000).

Multiple pectinase isozymes are relatively common in phytopathogenic fungi and these isozymes typically differ in their regulation (Annis \& Goodwin, 1997). Different pectinase isozymes may be active in a stagespecific manner during the saprotrophic, biotrophic or necrotrophic phases of infection, synergistically, at the same time or during several phases of infection. For example, Fusarium solani f. sp. pisi possesses at least four PEL genes: pelA is induced by oligomers produced by $p e l B$; pelB is constitutively expressed; pelD is only expressed in planta; and pelC may encode an intracellular PEL that degrades oligomers generated by other pectinases (González-Candelas \& Kolattukudy, 1992; Guo et al., 1995a, b, 1996). These four genes are believed to act synergistically to provide rapid degradation of the pectin, and although disruption of pelA or pelD alone did not affect virulence, a loss in virulence was observed when both pelA and pelD were disrupted (Rogers et al., 2000).

A further examination of Cgm has revealed that the fungus contains additional pectinase genes. The work presented here describes the characterization of two PNL genes, pnl-1 and pnl-2, from Cgm. These encode extracellular PNLs that differ considerably in their expression in pure culture and in their expression during infection. In addition, $p n l-1$ has a novel structure that has not previously been described for any pectinase gene.

\section{METHODS}

Biological materials and inoculations. Cgm was grown in the dark on potato dextrose agar (PDA; Difco) at $22{ }^{\circ} \mathrm{C}$ for 8 days to obtain conidia for inoculation. Round-leaved mallow plants were grown as previously described (Wei et al., 1997); inoculations were performed as described by Shih et al. (2000).
Fungal in vitro culture. Conidia from 8-day-old cultures, grown on PDA, were transferred to liquid medium to give a final concentration of $1 \times 10^{7}$ conidia $\mathrm{ml}^{-1}$ and were grown at $22{ }^{\circ} \mathrm{C}$ with shaking at 120 r.p.m. The medium was a minimal salts broth $\left(0.3 \mathrm{~g} \mathrm{NaNO}_{3} \mathrm{l}^{-1} ; 0.5 \mathrm{~g} \mathrm{KCl} \mathrm{l}^{-1} ; 0.5 \mathrm{~g} \mathrm{MgSO}_{4} .7 \mathrm{H}_{2} \mathrm{O}\right.$ $\mathrm{l}^{-1} ; 0 \cdot 01 \mathrm{~g} \mathrm{FeSO}_{4} .7 \mathrm{H}_{2} \mathrm{O} \mathrm{l}^{-1} ; 1 \cdot 0 \mathrm{~g} \mathrm{~K}_{2} \mathrm{HPO}_{4} \mathrm{l}^{-1}$ ) with a sole carbon source of either $2 \%$ glucose, $0.5 \%$ apple pectin (galacturonic acid content, $77.5 \%$; methoxy content, $7.8 \%$; Sigma), $0.5 \%$ mallow-leaf cell wall extracted according to Mankarios \& Friend (1980) or $0.5 \%$ apple pectin plus $0.5 \%$ MCWE. The mycelium of a 3-day-old culture of Cgm was harvested by filtration through two layers of Miracloth (Calbiochem), ground to a fine powder in liquid nitrogen and stored at $-70^{\circ} \mathrm{C}$ for RNA extraction.

DNA and RNA isolation. Genomic DNA was isolated from the mycelia of 7-day-old cultures of Cgm, Colletotrichum graminicola, Colletotrichum gloeosporioides $\mathrm{f}$. sp. hyperici and Colletotrichum lindemuthianum grown on PDA covered with cellophane (Flexel), as described by Goodwin et al. (2000). Total RNA from fungus, host and infected host tissue was extracted according to the method of Chen et al. (2000).

Amplification of partial pnl fragments. Genomic DNA from Cgm was used as a template for PCR with primers PL5 $\left(5^{\prime}\right.$ CAGCGGTGTCATCAAGGG-3') and PL3 (5'-AACAGTGGTCAGATCCAGAC-3' ; bold primer is degenerate, A or G), corresponding to the peptide sequences SGVIKG and VWIDHV, respectively, which are highly conserved among several known pnl and pel genes (Templeton et al., 1994). The PCR conditions used were one cycle of $5 \mathrm{~min}$ at $94{ }^{\circ} \mathrm{C}, 2 \mathrm{~min}$ at $65^{\circ} \mathrm{C}$ and $3 \mathrm{~min}$ at $72{ }^{\circ} \mathrm{C}$, followed by 39 cycles of $1 \mathrm{~min}$ at $94{ }^{\circ} \mathrm{C}, 1 \mathrm{~min}$ at $65^{\circ} \mathrm{C}$ and $1.5 \mathrm{~min}$ at $72^{\circ} \mathrm{C}$, with a final extension for $10 \mathrm{~min}$ at $72^{\circ} \mathrm{C}$. PCR products from this amplification were made blunt-ended using DNA polymerase I Klenow fragment (Amersham Pharmacia). The PCR products were then cloned into pBluescript $\mathrm{KS}^{-}$(Stratagene).

cDNA-library screening. A cDNA library was constructed in 2ZAPII (Stratagene), according to the manufacturer's instructions, using poly $(\mathrm{A})^{+} \mathrm{RNA}$ isolated from the infected area of mallow leaves at $72-96 \mathrm{~h}$ after inoculation with Cgm (the transition period from LPH to TSH). The cloned pel-1 and pel-2 PCR products, obtained using primers PL5 and PL3 with genomic DNA from Cgm, were labelled using the Random Primed DNA Labelling Kit (Roche Diagnostics) and were used to screen the cDNA library. Plaque-lifts were done with a MagnaGraph nylon transfer membrane (MSI Micron Separations) according to Sambrook et al. (1989). Hybridizations of plaque-lifts were performed according to the manufacturer's protocols (MSI Micron Separations). The blots were washed in $1 \times$ SSC at $42^{\circ} \mathrm{C}$ (Sambrook et al., 1989). Selected cDNA clones in the $\lambda Z$ APII library were transformed into pBluescriptII SK ${ }^{-}$by the in vivo excision procedure (Stratagene).

Rapid amplification of CDNA ends (RACE). This procedure was performed as described by Shih et al. (2000), with the following modifications. Primers AP1 (5'-CCATCCTAATACGACTCACTATAGGGC-3') and PL5 were used in the amplification of the $3^{\prime}$ RACE product of pnl-2; primers AP1 and PNL2 (5'-CCGAGGACGATGTGCTGGC-3') were used for amplification of the $5^{\prime}$ RACE product. Primer PNL2 was designed based on the sequence of the $3^{\prime}$ RACE product of pnl-2. PCR conditions for the amplification of the $5^{\prime}$ RACE product were $1 \mathrm{~min}$ at $94^{\circ} \mathrm{C}$, followed by 30 cycles of $15 \mathrm{~s}$ at $94{ }^{\circ} \mathrm{C}, 30 \mathrm{~s}$ at $66^{\circ} \mathrm{C}$ and $45 \mathrm{~s}$ at $72{ }^{\circ} \mathrm{C}$, with a final extension of 3 min at $72^{\circ} \mathrm{C}$. The PCR conditions for amplification of the $3^{\prime}$ RACE product consisted of $1 \mathrm{~min}$ at $94^{\circ} \mathrm{C}$, followed by 25 cycles of $45 \mathrm{~s}$ at $94{ }^{\circ} \mathrm{C}$ and $2 \mathrm{~min}$ at $68^{\circ} \mathrm{C}$. The primers PNL2F 
(5'-CACACCGACCTCTACATTC-3') and PNL2R (5'-GTCCTCGACGGTAAGTAAG-3'), which were used for the amplification of the full-length $p n l-2$ cDNA, were designed based on sequences of the overlapping $5^{\prime}$ and $3^{\prime}$ RACE products. The PCR conditions for cloning the full-length $p n l-2$ cDNA were the same as those described for $5^{\prime}$ RACE, except that the annealing temperature was $58^{\circ} \mathrm{C}$. PCR products were cloned according to Shih et al. (2000).

Sequence analyses. Both strands were sequenced by the dyeterminator method on an automated DNA sequencer (model 377; Applied Biosystems). Computer analysis and phenogram construction based on the nucleotide and deduced amino acid sequences was performed according to Shih et al. (2000).

Northern and Southern hybridizations. These were done with MagnaGraph nylon transfer membranes, as described above for the plaque-lifts. Hybridization probes were prepared from full-length cDNA clones of $p n l-1$ and $p n l-2$, and were labelled as previously described. The blots were washed in $1 \times$ SSPE (for Northern) or $1 \times \mathrm{SSC}$ (for Southern) at $42{ }^{\circ} \mathrm{C}$ for medium stringency and in $0 \cdot 1 \times \mathrm{SSPE}$ or $0 \cdot 1 \times \mathrm{SSC}$ at $65^{\circ} \mathrm{C}$ for high stringency (Sambrook et al., 1989).

RT-PCR analyses. DNA-free total RNA was extracted from inoculated and un-inoculated mallow leaves, treated with RNase-free DNase (Life Technologies), and reverse transcribed into cDNA with SUPERSCRIPT II (Life Technologies) using oligo(dT) primers. For RT-PCR of $p n l-1$, the cDNA was used with the $p n l-1$-specific primers PNL1F $\left(5^{\prime}\right.$-ATGAAGTCGGCTTCAGCC-3') and PNL1R (5'-ATGGGTGGTGACTTAGAC-3'); the PCR procedure was the same as previously described for the PL5 and PL3 primers. Amplification of actA from the same samples was performed according to Goodwin et al. (2000). Relative RT-PCR for co-amplification of pnl-2 and actA (Jin et al., 1999) was performed according to Goodwin et al. (2000), with the following modifications. Primers PNL2F and PNL2 were used to amplify a portion of pnl-2; the PCR conditions used were $3 \mathrm{~min}$ at $94^{\circ} \mathrm{C}$, followed by 35 cycles of $50 \mathrm{~s}$ at $94^{\circ} \mathrm{C}, 50 \mathrm{~s}$ at $56^{\circ} \mathrm{C}$, and $60 \mathrm{~s}$ at $72^{\circ} \mathrm{C}$, and a final extension of $7 \mathrm{~min}$ at $72^{\circ} \mathrm{C}$. All experiments were repeated at least twice.

\section{RESULTS}

\section{Cloning of pnl-1 and pnl-2}

PCR amplification of the genomic DNA of Cgm with primers for highly conserved regions of PNLs (Templeton et al., 1994) resulted in three fragments, of 320, 220 and $150 \mathrm{bp}$. The 220 and $150 \mathrm{bp}$ PCR products had high amino acid similarity to known PNLs. The $150 \mathrm{bp}$ fragment was designated $p n l-1$ and the $220 \mathrm{bp}$ fragment was designated pnl-2. The $320 \mathrm{bp}$ fragment had high similarity to PEL sequences and was designated pel-1 (Shih et al., 2000). The 220 and 150 bp PCR fragments were used to probe a cDNA library that was constructed using poly $(\mathrm{A})^{+}$RNA isolated from infected mallow leaves at 72-96 h after inoculation. Three full-length cDNA clones were found upon screening approximately $1 \cdot 1 \times 10^{5}$ plaques with the $150 \mathrm{bp} p n l-1$ probe; all three matched exactly with the sequence of pnl-1. Based on the sequence of the $220 \mathrm{bp}$ fragment of $p n l-2$, two overlapping fragments covering the entire length of the pnl-2 ORF were cloned by $5^{\prime}$ and $3^{\prime}$ RACE. A full-length cDNA of $p n l-2$ was then amplified and cloned.

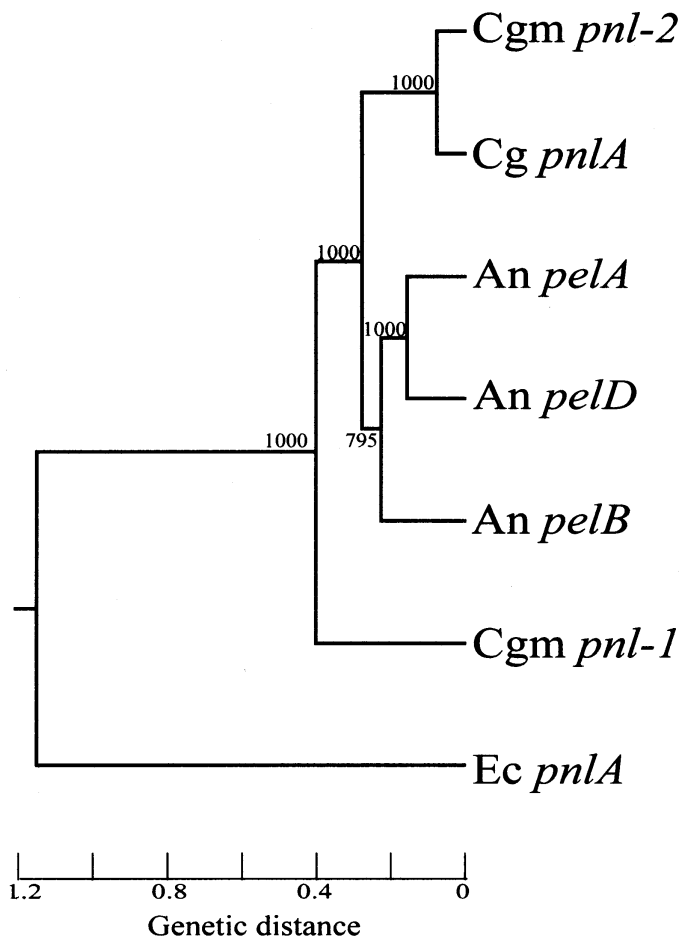

Fig. 1. Phenogram, produced by the neighbour-joining method, based on the genetic distances between the deduced amino acid sequences of pnl genes. The sequences are: pelA, pelB and pelD from Aspergillus niger (An) (GenBank accession nos Q01172, S23573, P22864, respectively); pnIA from Colletotrichum gloeosporioides (Cg) (L22857); pnl-1 from Cgm (this study); and pnlA from Erwinia carotovora subsp. carotovora (Ec) (A37322). Bootstrap values for 1000 replications are shown near the corresponding branches.

\section{Sequence analyses}

pnl-1 (GenBank accession no. AF158256) encoded a putative protein of 479 aa. The predicted amino acid sequence from $p n l-1$ had a signal-peptide-cleavage site between Ala20 and Gln21 that conformed with the $(-3$, $-1)$ rule (von Heijine, 1991). The mature protein from pnl-1 would have a molecular mass of $47.3 \mathrm{kDa}$, consisting of $459 \mathrm{aa}$, and a pI of 5.5. Two potential $N$ glycosylation sites were found at Asn39 and Asn124. Codon usage was highly biased, with $61 \%$ of all codons having a $\mathrm{C}$ in the third position $(\mathrm{C}, 61 \%$;, $21 \%$; $12 \% ; \mathrm{A}, 5 \%$ ).

pnl-2 (GenBank accession no. AF156984) encoded a putative protein of 379 a with a signal-peptide-cleavage site between Ala19 and Ala20 that conformed with the $(-3,-1)$ rule (von Heijine, 1991). The mature protein would have a molecular mass of $37.5 \mathrm{kDa}$, consisting of 360 aa, one potential N-glycosylation site at Asn129 and a pI of $8 \cdot 3$. Codon usage was also highly biased, with $72 \%$ of all codons having a $\mathrm{C}$ in the third position (C, 72\% ; G, 17\% ; T, 9\% ; A, 2\%).

The amino acid sequences from $p n l-1$ and $p n l-2$ were compared with those of other fungal and bacterial PNLs (Fig. 1). The deduced protein sequence from $p n l-1$ had 


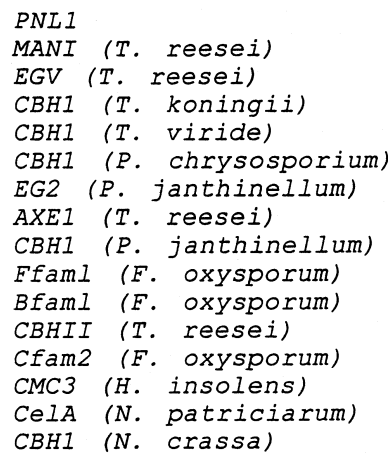

SVALYGOCGGOGYSGATTC. ASGKCELVNDWYSOCV CSPLYGQCGGSGYTGPTCC. AQGTCIYSNYWYSQCL QQTLYGQCGGAGWTGPTTCQAPGTCKVQ . . WYSQCL TQSHYGQCGGIGYSGPTVCASGTTCQVLNPYYSQCI TOTHYGQCGGIGYIGPTVCASGSTCQVLNPYYSQCI TVPQWGQCGGI GYTGSTTCAS PYTCHVLNPYYSQCY QQTAWGQCGGQGWTGATTCVSGYYCSFQNNWYSQCI TOTHWGQCGGQGWT GPTQCESGTTCQVISQWYSQCI GARDWAQCGGNGWTGPTTCVSPYTCTKQNDWYSQCI QAPIWGQCGGNGWTGATTCASGLKCEKINDWYYQCV SNGVWAOCGGQNWSGT PCCTSGNKCVKLNDFYSQCQ CSSVWGQCGGQNWSGPTCCASGSTCVYSNDYYSQCI SVDQWGQCGGQNYSGPTTCKS P FTCKKINDFYSQCQ OGGAWOOCGGVGFSGSTSCVSGYTCVYLNDWYSQCQ CGGAWAOCGGENFHGDKCCVSGHTCVS INOWY SOCO CAAHWAQCGGIGESGPTTCPEPYTCAKDHDIYSQCV
Fig. 2. Alignment of the C-terminal domain of Pnl1 of Cgm with the CBDs of cellulases (CBH, EGV, EG, Bfam1, Cfam2, Ffam1, CMC and CelA) a mannanase (MANI) and an acetylxylan esterase (AXEI) from various fungi. Sequences of CBDs are: $C B H I$, EGV, MANI and AXEI from Trichoderma reesei (GenBank accession nos P07987, S60143, AAA34208 and S71334, respectively); CBHI from Trichoderma koningii (S45380); CBHI from Trichoderma viride (CAA37878); $\mathrm{CBHI}$ from Phanerochaete chrysosporium (AAB46373); EG2 and $\mathrm{CBH} 1$ from Penicillum janthinellum (CAA61740, JU0510); Bfam1, Cfam2, Ffam1 from Fusarium oxysporum (P46236, P46238 and P46239, respectively); CMC3 from Humicola insolens (Q12624); CBH1 from Neurospora crassa (S42093); and CelA from Neocallimastix patriciarum (AAC49315). Gaps are indicated by dots; conserved aromatic residues are marked in bold.

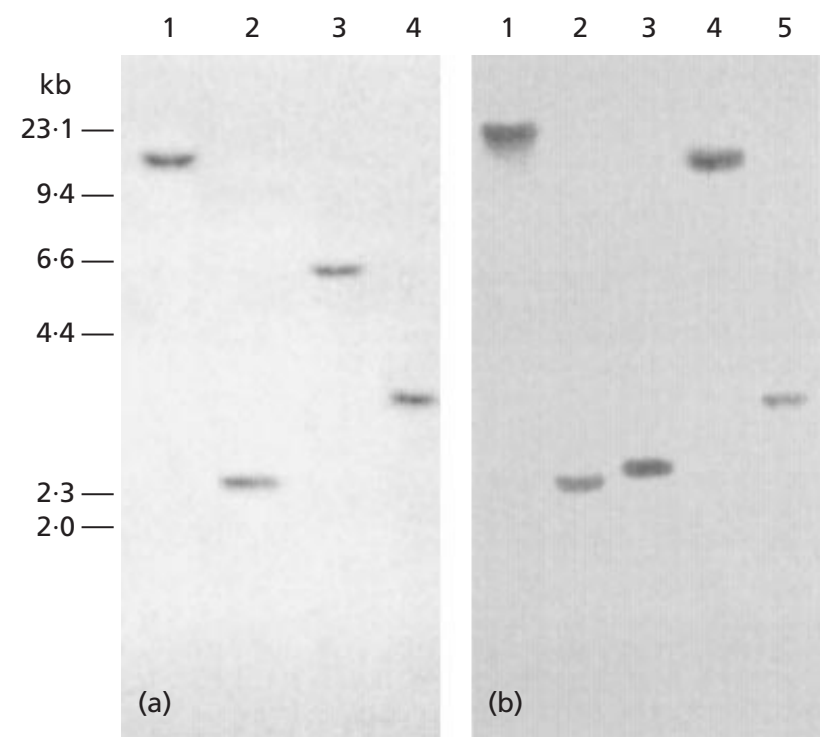

Fig. 3. Southern blots of Cgm DNA probed with pnl-1 or pnl-2 of Cgm. (a) Southern blot of Cgm DNA probed with pnl-1 and digested with the following enzymes. Lanes: 1, BamHI; 2, HindIII; 3, Xbal; and 4, Xhol. (b) Southern blot of Cgm DNA probed with pnl-2 and digested with the following enzymes. Lanes: 1, BamHI; 2, Hindlll; 3, Pstl; 4, Sacl; and 5, Xhol. Molecular size markers are shown on the left hand side of the figure.

$41-46 \%$ similarity (identity and conserved substitutions) to PNLs of other fungi. pnl-2 was closely related to the pnlA gene of Glomerella cingulata $(93 \%$ similarity). pelA, pelB and pelD all clustered together, which is not surprising since these three PNL genes are all from Aspergillus niger.

All 27 invariant amino acids, which are conserved in the extracellular superfamiliy of PNLs (Henrissat et al., 1995), were found in the deduced amino acid sequences of pnl-1 and pnl-2. However, Pnl1 is unique because it also contains an extra C-terminal sequence, which shows high similarity to a cellulose-binding domain (CBD) found in some cellulases and to other CWDEs from several different fungi (Fig. 2) (Margolles-Clark et al., 1996; Saloheimo et al., 1994; Sheppard et al., 1994; Tomme et al., 1995). The CBD of Pnl1 contains the characteristic amino acids found in other CBDs, including four conserved aromatic residues (Tyr449, Tyr457, Trp474, Tyr475), which are believed to be important for the interaction with cellulose, and four cysteine residues (Cys452, Cys463, Cys468, Cys478), which possibly form two $S-S$ bridges to stabilize the structure (Margolles-Clark et al., 1996; Saloheimo et al., 1994; Tomme et al., 1995). The putative CBD of Pnl1 is separated from the main PNL catalytic domain by a sequence containing three highly flexible regions rich in serine, threonine and glycine, which is similar to the linker sequences of other CBDs (Margolles-Clark et al., 1996; Saloheimo et al., 1994; Tomme et al., 1995).

Although $p n l-1$ was the most distantly related fungal PNL gene, with an overall similarity of only $49 \%$ to $p n l$ 2 , this difference is exaggerated by the CBD and linker that is encoded by $p n l-1$ but is absent in $p n l-2$. If the CBD and linker of $p n l-1$ were excluded from this comparison, then the overall similarity between $p n l-1$ and $p n l-2$ rose to $63 \%$.

\section{Southern-hybridization analysis}

$p n l-1$ and $p n l-2$ are likely to be single-copy genes in the Cgm genome, as indicated by single bands in each of the digests in Southern hybridizations (Fig. 3). Hybridization with $p n l-1$ under low-stringency conditions revealed only one additional weakly hybridizing band, indicating that Cgm may have only two PNL genes (data not shown). Because $p n l-1$ is unique in having a CBD, an examination for homologues of $p n l-1$ was made in several related fungi; a single major hybridization band of about the same size as the one seen for Cgm was 


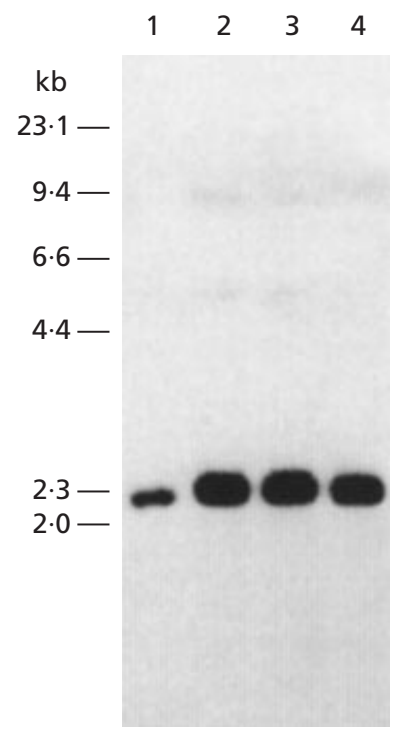

Fig. 4. Southern blots of pnl-1 homologues from several Colletotrichum species, in which EcoRV-generated genomic digests were hybridized with the pnl-1 gene of Cgm. Lanes: 1, C. gloeosporioides f. sp. malvae; 2, C. gloeosporioides $f$. sp. hyperici; 3, C. lindemuthianum; and 4, C. graminicola. Molecular size markers are shown at the left of the figure.

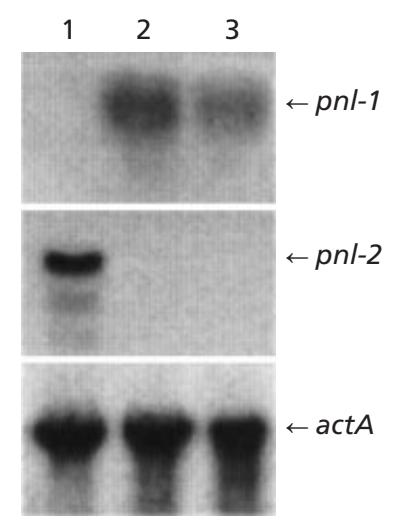

Fig. 5. Northern blots of total RNA extracted from 3-day-old mycelia grown in liquid medium containing either MCWE (lane 1 ), pectin (lane 2) or glucose (lane 3 ) as the sole carbon source. Membranes were hybridized with pnl-1, pnl-2 or actA of Cgm.

observed (Fig. 4). However, one extra, faint band (of approx. $9.4 \mathrm{~kb}$ ) in C. graminicola and two extra, faint bands (of approx. 8.9 and $5.3 \mathrm{~kb}$ ) in C. gloeosporioides f. sp. hyperici and C. lindemuthianum were also observed, which were more pronounced under mediumstringency conditions.

\section{Expression of $p n l-1$ and $p n l-2$ in culture}

Northern-hybridization analyses using RNA from mycelia grown in medium with either MCWE, pectin or glucose as sole carbon source revealed a strong hybridization signal for $p n l-2$ in MCWE cultures, whereas no expression was detected in the pectin or glucose cultures

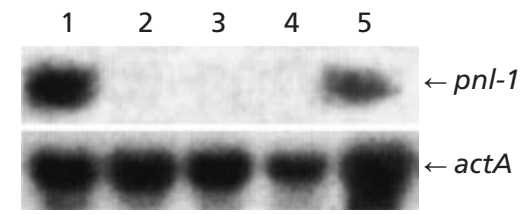

Fig. 6. Northern blots of total RNA from Cgm from infected mallow leaves at $96 \mathrm{~h}$ after inoculation (lane 1), or mycelia grown in medium containing either: lane 2, MCWE as sole carbon source; lane 3, MCWE plus pectin $(1: 1, w: w)$ as carbon source; lane 4, MCWE plus pectin (1:3, w:w) as carbon source; or lane 5 , pectin as sole carbon source. Membranes were hybridized with pnl-1 or actA of Cgm.

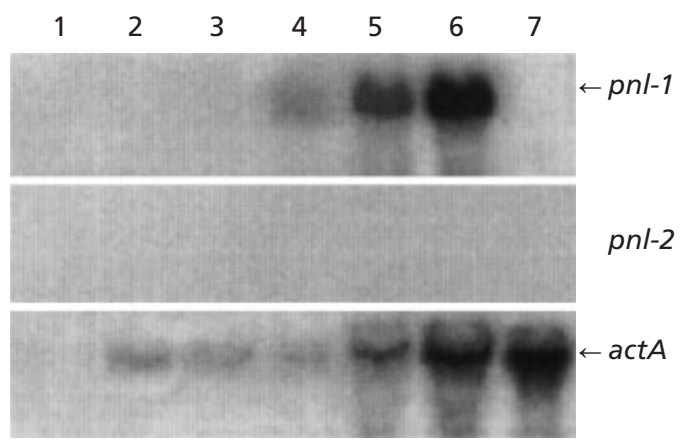

Fig. 7. Northern blots of total RNA extracted from mallow leaves inoculated with Cgm and probed with pnl-1, pnl-2 or actA. Lanes: 1, un-inoculated mallow leaves; $2,24 \mathrm{~h}$ after inoculation; $3,48 \mathrm{~h}$ after inoculation; $4,72 \mathrm{~h}$ after inoculation; 5, $96 \mathrm{~h}$ after inoculation; and $6,120 \mathrm{~h}$ after inoculation. Lane 7 shows RNA extracted from the conidia of 8-day-old cultures of Cgm grown on PDA plates.

(Fig. 5). In contrast, pnl-1 showed expression in pectin cultures, somewhat lower expression in glucose cultures, but no detectable expression in MCWE cultures.

The inability to detect pnl-1 transcripts from mycelia grown on MCWE could be due to the lack of an inducer or the presence of a repressor in the MCWE. To discriminate between these possibilities, Cgm was cultured on medium containing both MCWE and pectin. pnl-1 transcripts were not detected with the mixture of pectin and MCWE, even though the gene was expressed when pectin was the sole carbon source (Fig. 6). Therefore, it is likely that a repressor(s) exists in MCWE, which somehow inhibits $p n l-1$ expression.

\section{Expression of $p n l-1$ and $p n l-2$ during infection}

Northern hybridizations of total RNA from mallow leaves inoculated with Cgm were used to examine expression of $p n l-1, p n l-2$ and act A [a constitutively expressed actin gene of $\mathrm{Cgm}$ that has been used to monitor the growth of the fungus during infection (Jin et al., 1999)]. Transcript levels of act $A$ were first detectable at $24 \mathrm{~h}$ after inoculation but remained low until $72-96 \mathrm{~h}$ after infection, when a considerable increase occurred. After this time there was only a slight increase in transcript levels (Fig. 7). Transcripts of pnl-1 were not 


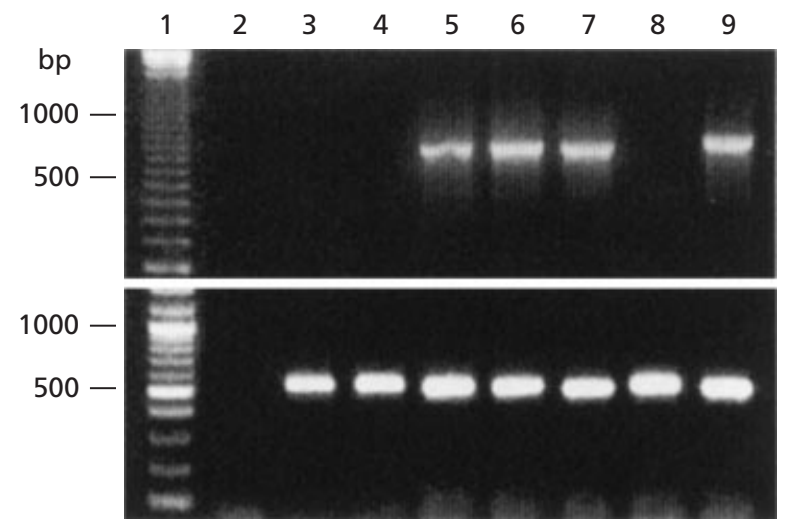

Fig. 8. RT-PCR products of pnl-1 (top panel) or actA (bottom panel) from un-inoculated mallow leaves and from mallow leaves at various time intervals after inoculation with $\mathrm{Cgm}$. Lanes: 1, molecular mass ladder; 2, un-inoculated mallow leaves; 3, $24 \mathrm{~h}$ after inoculation; 4, $48 \mathrm{~h}$ after inoculation; 5, $72 \mathrm{~h}$ after inoculation; $6,96 \mathrm{~h}$ after inoculation; $7,120 \mathrm{~h}$ after inoculation; 8, RNA extracted from the conidia of 8-day-old cultures grown on PDA plates; and lane 9, genomic DNA of Cgm.

detected until $72 \mathrm{~h}$ after inoculation, with a major accumulation occurring at 96 and $120 \mathrm{~h}$ after inoculation. In contrast, no transcripts of $p n l-2$ could be detected from infected plants by Northern hybridization. Transcripts of actA, but not $p n l-1$ or $p n l-2$, could be detected from spores grown on PDA using Northern hybridization (Fig. 7).

Microscopy studies showed that the appressorium had developed by $24 \mathrm{~h}$ after inoculation, that penetration of the epidermal cell and infection vesicle formation had occurred by $48 \mathrm{~h}$ after inoculation and that LPH was growing intracellularly through adjacent epidermal cells and then intercellularly between mesophyll cells by $64 \mathrm{~h}$ after inoculation. The major increase in act $A$ transcripts and the appearance of pnl-1 transcripts, observed by Northern hybridizations at $72 \mathrm{~h}$ after inoculation, corresponded with the appearance of TSH, necrotrophy and tissue maceration.

The expression of $p n l-1$ and $p n l-2$ during infection was also investigated by RT-PCR, using primers that spanned introns. Amplification with pnl-1-specific primers detected a band of the expected size at $72 \mathrm{~h}$ after inoculation, and at subsequent time points, but no pnl1 transcripts were detected in the biotrophic phase or from spores grown on PDA (Fig. 8). These results confirm the Northern hybridization results. The lack of pnl-1 transcripts in spores and during the biotrophic phase was not due to a lack of cDNA, as amplification of act $A$ was possible whenever the fungus was present (Fig. 8). For pnl-2, relative RT-PCR (Goodwin et al., 2000) was performed, where pnl-2 was co-amplified with the constitutively expressed act $A$ gene as an internal control so that expression levels could be compared between the two genes. Although pnl-2 expression could not be detected by Northern hybridization, it could be detected by relative RT-PCR, with detection beginning

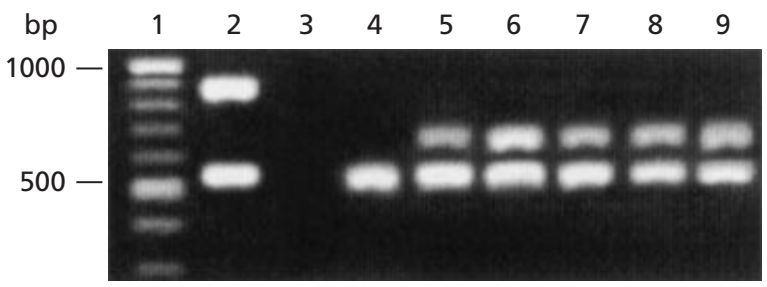

Fig. 9. Relative RT-PCR of pnl-2 (upper band) and actA (lower band) from un-inoculated mallow leaves or mallow leaves at various time intervals after inoculation with Cgm. Lanes: 1, molecular mass marker; 2, genomic DNA of Cgm; 3, uninoculated mallow leaves; $4,24 \mathrm{~h}$ after inoculation; $5,48 \mathrm{~h}$ after inoculation; $6,72 \mathrm{~h}$ after inoculation; $7,96 \mathrm{~h}$ after inoculation; 8, $120 \mathrm{~h}$ after inoculation; and 9, RNA extracted from the conidia of 8-day-old cultures grown on PDA plates.

in the biotrophic phase at $48 \mathrm{~h}$ after inoculation (Fig. 9). Transcripts of $p n l-2$ were also detectable by RT-PCR from spores grown on PDA. During infection, expression of pnl-2 was first detected at $48 \mathrm{~h}$ after inoculation and thereafter appeared to be expressed at a relatively constant level compared to actA (Fig. 9).

\section{DISCUSSION}

Cgm contains at least two PNL genes in addition to two PEL genes, previously described by Shih et al. (2000). Although amplification of genomic DNA from Cgm with primers from highly conserved regions of PNLs resulted in portions of $p n l-1$ and $p n l-2$, only $p n l-1$ was found by screening a cDNA library constructed from RNA isolated from infected leaves at the transition from LPH to TSH. This corresponds with the finding that only pnl-1 transcripts could be detected by Northernblot analyses of infected tissue.

Since $p n l-2$ transcripts were not detected in the cDNA library or by Northern hybridizations, but were detected by RT-PCR from infected tissue, it appears that $p n l-2$ had a much lower level of expression during infection than pnl-1. pnl-2 is also the first pectinase of $\mathrm{Cgm}$ identified thus far that is expressed in the biotrophic phase of infection. Biotrophic and hemibiotrophic fungal pathogens may need to regulate their CWDEs to avoid tissue maceration and the production of oligogalacturonate products that may elicit plant-defence responses (Keon et al., 1987). One way to achieve this is by having very low levels of expression; in general, biotrophic fungi are reported to have much lower levels of CWDEs compared to those of necrotrophs (Keon et al., 1987). Although pnl-2 is also expressed during the necrotrophic phase, its level of expression remains relatively low (i.e. only detectable by RT-PCR).

It is possible that $p n l-2$ expression was relatively low during infection because it may be more sensitive to catabolite repression. Expression of $p n l-2$ was relatively high (i.e. detectable by Northern hybridization) in cultures grown with MCWE, but was not detectable by Northern hybridization in cultures grown with glucose, which is well known to repress pectinase genes. Ex- 
pression was also not detected in cultures grown with purified apple pectin, which is more soluble than MCWE and would not only provide more inducers for pectinases but would also yield catabolites more rapidly than MCWE.

Keon et al. (1987) compared the features of the CWDEs of biotrophs, necrotrophs and hemibiotophs. For biotrophs and the biotrophic phase of hemibiotrophs hostcell-wall penetration is highly localized, with minimal wall degradation, but for many necrotrophs and the necrotrophic phase of hemibiotrophs, widespread cellwall degradation and maceration occurs. Catabolite repression provides the main means of regulating fungal CWDEs and can be caused by even very low levels of sugars. Keon et al. (1987) hypothesized that for hemibiotrophs, such as certain Colletotrichum spp., the switch from biotrophy to necrotrophy may be related to the fungal CWDEs ceasing to be affected by host sugars. One way that a hemibiotrophic fungus could do this is by having different CWDEs at different stages of disease development, through the production of multiple isozymes that are regulated in different ways.

$p n l-1$ of Cgm was regulated quite differently to $p n l-2$. In culture, $p n l-1$ transcripts were detected when pectin was the sole carbon source and were only partially repressed by the presence of glucose, indicating that regulation by catabolite repression was limited. This is similar to pel2 of Cgm, which was also expressed in cultures with pectin and glucose (Shih et al., 2000). During infection, pnl-1 appeared to be expressed at a considerably higher level (i.e. detectable by Northern hybridization) than pnl-2, and expression during infection was associated with development of necrotic symptoms. This is also similar to the expression of pel-2 in infected tissue (Shih et al., 2000). Therefore, pnl-1 and pel-2 could be genes that are not greatly affected by host sugars and that are involved in the widespread cell-wall degradation associated with necrotrophy.

Expression of pnl-1 was undetectable when Cgm was grown on media with MCWE as a sole carbon source, indicating that expression of pnl-1 cannot be explained simply by substrate inducibility. The results when a combination of apple pectin and MCWE was used as carbon source showed that component(s) of the hostcell material inhibited $p n l-1$ expression. However, this inhibitory material apparently does not cause significant inhibition of pnl-1 expression during infection. The extraction method employed to obtain cell-wall extract yields a material that is largely free of pigments, lipids and other cytoplasmic contaminants, but in which denatured proteins remain associated with the cell-wall polysaccharides. One possibility is that the inhibitor of pnl-1 expression is a compound released from a particular polysaccharide that could be attacked by CWDEs in medium with MCWE but was not readily available for enzymic digestion in plant tissue because it was associated with phenols, proteins or ions. It would be interesting to isolate the compound(s) responsible for this inhibition and determine how it differs between MCWE cultures and mallow leaves.
A unique feature of the predicted Pnl1 protein is that it contains a CBD linked by a hinge to a PNL catalytic domain. CBDs are commonly found as ancillary domains in cellulases, hemicellulases, xylanases, mannanases and acetylxylan esterases (Tomme et al., 1995). Removal of the CBD, genetically or proteolytically, affects enzyme activity on various cellulosic substrates. It has been hypothesized that CBDs enhance enzyme activity to their substrates either by increasing the effective enzyme concentration on the substrate surface by binding to the substrate, or by making the substrate more accessible to the catalytic domain (Tomme et al., 1995). Pnl1 is the first example of a CBD in a PNL. However, it remains to be seen whether the CBD participates in positioning Pnl1 or whether it directly affects the enzymic activity.

The presence of CBD in Pnl1 implies that pnl-1 may represent a member of a novel PNL gene family that is common to a number of fungi. Southern hybridization demonstrated that pnl-1 homologues were present in at least several other Colletotrichum species, and this has been confirmed by the cloning and sequencing of a highly similar $p n l$ sequence with a CBD from C. lindemuthianum (Y. Wei \& P.H. Goodwin, unpublished data).

One indication of the role of $\mathrm{CBDs}$ in virulence is indicated by the fact that CBDs are common among cellulases of saprophytic fungi, whereas cellulases from plant-pathogenic fungi often lack CBDs (Müller et al., 1997; Sposato et al., 1995; Wang \& Jones, 1996; Wang \& Nuss, 1995). Wang \& Jones (1996) showed that a cellulase with a CBD from Trichoderma reesei, a saprophyte, caused tissue necrosis when applied to plant tissue, but equivalent levels of a cellulase without a CBD from Macrophomina phaseolina, a plant-pathogenic fungus, did not result in necrosis. For Phytophthora parasitica var. nicotianae, a cell-wall glycoprotein was found to have both elicitor activity and two repeated domains with a motif resembling the fungal CBD consensus sequence (Mateos et al., 1997). Infiltration of tobacco leaves with this protein elicited necrosis- and defence-gene expression. Although the role of the CBDs in CWDEs of plant-pathogenic fungi remains to be determined, it is interesting to speculate that CBDs may have some function in eliciting host necrosis. For Cgm, expression of the CBD-containing pnl-1 gene was associated with the appearance of host necrosis, whereas expression of $p n l-2$, which lacks a CBD, was observed prior to host necrosis.

The cytology of the interaction between Cgm and mallow supports a role for CWDEs during infection (Morin et al., 1996; Wei et al., 1997). During the biotrophic phase LPH is highly constricted as it penetrates host cell walls, but in the necrotrophic phase extensive host-cell maceration and no constriction of TSH occurs during cell-wall penetration. Therefore, it appears that LPH and TSH produce different types of cell-wall degradation during infection. LPH may be highly constricted at the plant cell wall as a result of a 
relatively low level of localized wall degradation, which may be necessary to permit fungal growth while maintaining biotrophy. However, extensive cell maceration by TSH indicates larger amounts of moredamaging CWDEs. Wubben et al. (2000) hypothesized that fungal pathogens have large pectinase gene families to allow for complex expression patterns that can be altered for different conditions. In this study, we have shown that in addition to pel-1 and pel-2 (Shih et al., 2000), Cgm also contains two PNL genes, pnl-1 and pnl2 , both of which are expressed during infection. However, the differences in their expression patterns and in the products that they encode may be related to the need for Cgm to have different types of cell-wall penetration during the biotrophic and necrotrophic phases of growth in host tissue.

\section{ACKNOWLEDGEMENTS}

This research was supported by the Natural Sciences and Engineering Research Council of Canada and the Ontario Ministry of Agriculture, Food and Rural Affairs.

\section{REFERENCES}

Annis, S. \& Goodwin, P. H. (1997). Recent advances in the molecular genetics of plant cell wall-degrading enzymes produced by plant pathogenic fungi. Eur J Plant Pathol 103, 1-14.

Chen, C. Y. J., Jin, S. \& Goodwin, P. H. (2000). An improved method for the isolation of total RNA from Malva pusilla tissues infected with Colletotrichum gloeosporioides. J Phytopathol 148, 57-60.

González-Candelas, L. \& Kolattukudy, P. E. (1992). Isolation and analysis of a novel inducible pectate lyase gene from the phytopathogenic fungus Fusarium solani f. sp. pisi (Nectria haematococca, mating population VI). J Bacteriol 174, 63436349.

Goodwin, P. H., Li, J. \& Jin, S. (2000). Evidence for sulfate derepression of an arylsulfatase gene of Colletotrichum gloeosporioides f. sp. malvae during infection of round-leaved mallow, Malva pusilla. Physiol Mol Plant Pathol 57, 169-176.

Guo, W. L., González-Candelas, L. \& Kolattukudy, P. E. (1995a). Cloning of a new pectate lyase gene pelC from Fusarium solani $\mathrm{f}$. sp. pisi (Nectria haematococca, mating type VI) and characterization of the gene product expressed in Pichia pastoris. Arch Biochem Biophys 323, 352-360.

Guo, W. L., González-Candelas, L. \& Kolattukudy, P. E. (1995b). Cloning of a novel constitutively expressed pectate lyase gene pelB from Fusarium solani f. sp. pisi (Nectria haematococca, mating type VI) and characterization of the gene product expressed in Pichia pastoris. J Bacteriol 177, 7070-7077.

Guo, W. L., González-Candelas, L. \& Kolattukudy, P. E. (1996). Identification of a novel pelD gene expressed uniquely in planta by Fusarium solani f. sp. pisi (Nectria haematococca, mating type VI) and characterization of its protein product as an endo-pectate lyase. Arch Biochem Biophys 332, 305-312.

Henrissat, B., Heffron, S. E., Yoder, M. D., Lietzke, S. E. \& Jurnak, F. (1995). Functional implications of structure-based sequence alignment of proteins in the extracellular pectate lyase superfamily. Plant Physiol 107, 963-976.

Jin, S., Xu, R., Wei, Y. \& Goodwin, P. H. (1999). Increased expression of a plant actin gene during a biotrophic interaction between round-leaved mallow, Malva pusilla, and Colletotrichum gloeosporioides f. sp. malvae. Planta 209, 487-494.

Keon, J. P. R., Byrde, R. J. W. \& Cooper, R. (1987). Some aspects of fungal enzymes that degrade plant cell walls. In Fungal Infection of Plants, pp. 133-157. Edited by G. I. Pegg \& P. G. Ayers. Cambridge: Cambridge University Press.

Makowski, R. M. D. \& Mortensen, K. (1992). The first mycoherbicide in Canada: Colletotrichum gloeosporioides f. sp. malvae for round-leaved mallow control. In: Proceedings of the First International Weed Control Congress, pp. 298-300. Edited by R. G. Richardson. Melbourne, Australia: Monarch University.

Mankarios, A. T. \& Friend, J. (1980). Polysaccharide-degrading enzymes of Botrytis allii and Sclerotium cepivorum. Enzyme production in culture and the effect of the enzymes on isolated onion cell walls. Physiol Plant Pathol 17, 93-104.

Margolles-Clark, E., Tenkanen, M., Söderlund, H. \& Penttilä, M. (1996). Acetyl xylan esterase from Trichoderma reesei contains an active-site serine residue and cellulose-binding domain. Eur J Biochem 237, 553-560.

Mateos, F. V., Rickauer, M. \& Esquerré-Tugayé, M.-T. (1997). Cloning and characterization of a cDNA encoding an elicitor of Phytophthora parasitica var. nicotianae that shows cellulosebinding and lectin-like activities. Mol Plant-Microbe Interact 10, 1045-1053.

Morin, L., Derby, J. A. L. \& Kokko, E. G. (1996). Infection process of Colletotrichum gloeosporioides f. sp. malvae on Malvaceae weeds. Mycol Res 100, 165-172.

Müller, U., Tenberge, K. B., Oeser, B. \& Tudzynski, P. (1997). cel1, probably encoding a cellobiohydrolase lacking the substrate binding domain, is expressed in the initial infection phase of Claviceps purpurea on secale cereal. Mol Plant-Microbe Interact 10, 268-279.

Rogers, L. M., Kim, Y. K., Guo, W., González-Candelas, L., Li, D. \& Kolattukudy, P. E. (2000). Requirement for either a host- or pectin-induced pectate lyase for infection of Pisum sativum by Nectria hematococca. Proc Natl Acad Sci U S A 97, 9813-9818.

Saloheimo, A., Henrissat, B., Hoffren, A., Teleman, O. \& Penttilä, M. (1994). A novel, small endoglucanase gene, egl5, from Trichoderma reesei isolated by expression in yeast. Mol Microbiol 13, 219-228.

Sambrook, J., Fritsch, E. F. \& Maniatis, T. A. (1989). Molecular Cloning: a Laboratory Manual, 2nd edn. Cold Spring Harbor, NY : Cold Spring Harbor Laboratory.

Sheppard, P. O., Grant, F. J., Oort, P. J., Sprecher, C. A., Foster, D. C., Hagen, F. S., Upshall, A., McKnight, G. L. \& O'Hara, P. J. (1994). The use of conserved cellulase family-specific sequences to clone cellulase homologue cDNAs from Fusarium oxysporum. Gene 150, 163-167.

Shih, J., Wei, Y. \& Goodwin, P. H. (2000). A comparison of the pectate lyase genes, pel-1 and pel-2, of Colletotrichum gloeosporioides f. sp. malvae and the relationship between their expression in culture and during necrotrophic infection. Gene 243, 139-150.

Sposato, P., Ahn, J.-H. \& Walton, J. D. (1995). Characterization and disruption of a gene in the maize pathogen Cochliobolus carbonum encoding a cellulase lacking a cellulose binding domain and hinge region. Mol Plant-Microbe Interact 8, 602-609.

Templeton, M. D., Sharrock, K. R., Bowen, J. K., Crowhurst, R. N. \& Rikkerink, H. A. (1994). The pectin lyase-encoding gene $(p n l)$ family from Glomerella cingulata: characterization of $p n l A$ and its expression in yeast. Gene 142, 141-146. 
Tomme, P., Warren, R. A. \& Gilkes, N. R. (1995). Cellulose hydrolysis by bacteria and fungi. In Advances in Microbial Physiology. Vol 37, pp. 1-88. Edited by R. K. Poole. New York, NY: Academic Press.

von Heijine, G. (1991). Signals for protein import into organelles. In Plant Molecular Biology 2, pp. 583-593. Edited by R. G. Hermann \& B. Larkins. New York, NY: Plenum.

Wang, H. \& Jones, R. W. (1996). Analyzing the role of a cellulose binding domain in fungal-plant interactions. Phytopathology $\mathbf{8 6}$, S91.

Wang, P. \& Nuss, D. L. (1995). Induction of a Cryphonectria parasitica cellobiohydrolase I gene is suppressed by hypovirus infection and regulated by a GTP-binding-protein-linked signaling pathway involved in fungal pathogenesis. Proc Natl Acad Sci US A 92, 11529-11533.
Wei, Y. D., Byer, K. N. \& Goodwin, P. H. (1997). Hemibiotrophic infection of round-leaved mallow by Colletotrichum gloeosporioides f. sp. malvae in relation to leaf senescence and reducing reagents. Mycol Res 101, 357-364.

Wubben, J. P., ten Have, A., van Kan, J. A. L. \& Visser, J. (2000). Regulation of endopolygalacturonase gene expression in Botrytis cinerea by galacturonic acid, ambient $\mathrm{pH}$ and carbon catabolite repression. Curr Genet 37, 152-157.

Yakoby, N., Beno-Moualem, D., Keen, N. T., Dinoor, A., Pines, O. \& Prusky, D. (2001). Colletotrichum gloeosporioides pelB is an important virulence factor in avocado fruit-fungus interaction. Mol Plant-Microbe Interact 14, 988-995.

Received 3 August 2001; revised 20 November 2001; accepted 23 November 2001. 